\title{
Fenretinide Lipid Matrix
}

National Cancer Institute

\section{Source}

National Cancer Institute. Fenretinide Lipid Matrix. NCI Thesaurus. Code C63482.

An orally bioavailable powder formulation of a synthetic phenylretinamide analogue of retinol with potential chemopreventive and antineoplastic activities. Fenretinide binds to and activates retinoic acid receptors (RARs), thereby inducing cell differentiation and apoptosis in some tumor cell types, including those of the colon, breast, prostate, and neuroblastoma. Independent of RAR activation, this agent also modulates gene expression that leads to ceramide-induced, caspase-independent programmed cell death (PCD) via effectors such as gang lioside GD3 and reactive oxygen species (ROS).

Compared to the capsule form, the powder contains a mixture of wheat flour, fats, and sugar that may contribute to the enhanced bioavailability of fenretinide. 